\title{
Epidemiological profile of poisoning patients in the emergency department of a tertiary care teaching hospital in South India
}

\author{
Srihari C. ${ }^{1}$, Ramakrishnan T.V. ${ }^{2}$, Aditya M. ${ }^{3}$ \\ ${ }^{1}$ Dr. Cattamanchi Srihari, Consultant and Adjunct Professor (Research), ${ }^{2}$ Dr. Trichur V. Ramakrishnan, Professor and \\ Head of the Department, ${ }^{3}$ Dr. Maddali Aditya, Consultant, all authors are affiliated with Department of Emergency \\ Medicine, Sri Ramachandra Medical College and Research Institute, Chennai. T.N. India.
}

Address for Correspondence: Name: Dr. Cattamanchi Srihari, Consultant and Adjunct Professor (Research), Department of Emergency Medicine, Sri Ramachandra Medical College and Research Institute, Porur, Chennai - 600 116. T. N. India. E-mail address: srihari@cattamanchi.in

\begin{abstract}
Background: Poisoning is a global public health issue and one of the common causes for visiting an emergency department (ED). A high index of suspicion based on etiology and clinical features is required to diagnose different types of poisons and their compounds. Aims: To define the epidemiological profile of patients registered in the ED with complaints of ingestion of poison, and to identify different types of poisons consumed, the duration of hospital stay and mortality due to these poisons. Methods: A retrospective analysis of patients presenting to the ED with complaints of poisoning. All patients registered in the ED with complaints of consumption of poison were included in the investigation. Patient charts with snake bites or scorpion stings were excluded. The medical charts with a discharge diagnosis of Poisoning during the study period were identified using the ICD-10-CM diagnosis codes categories T36-T65. Data was collected in a preformatted questionnaire. Results: In this study, 317 patients were enrolled, with a female predominance of $54.8 \%$. Thirty-one percent of the patients are 15 to 24 years old, and $11.35 \%$ are below five years. Thirty percent were students, $18.3 \%$ housewives and $6.62 \%$ were farmers, with $59.3 \%$ having access to poisons at their homes, $19.87 \%$ from the pharmacy and $14.9 \%$ from a neighborhood store. The intent of poisoning in $85.8 \%$ of the patients was suicidal. $34.7 \%$ patients ingested pesticides, $30.28 \%$ patients, presented with tablet overdose, $14.82 \%$ patients consumed rodenticides and insecticides, and $3.47 \%$ patients presented with oleander seed poisoning. About $32.17 \%$ of the patients were admitted to ICU. Nearly $53.94 \%$ patients were discharged within three days of hospitalization. The mortality rate due to poisoning was $4.1 \%$. Conclusion: This research article defines the epidemiological profile of poisoning patients registered in the emergency department, along with the common poisons used, duration of hospital stay and mortality due to poisoning.
\end{abstract}

Keywords: Poisoning; Emergency Department; Epidemiological Profile; South India.

\section{Introduction}

Poisoning is a global public health issue [1-5], and one of the common causes for visiting an emergency department (ED) [6-10]. Wide availability, easy access, and extensive use in medical, industrial, household and agricultural applications increase the risk, exposure, and incidence of poisoning [1,10]. The Oxford English Dictionary defines poison as "A substance that is capable of causing the illness or death of a living organism when introduced or absorbed." [11].

Manuscript received: $10^{\text {th }}$ February 2017

Reviewed: $18^{\text {th }}$ February 2017

Author Corrected: $25^{\text {th }}$ February 2017

Accepted for Publication: $4^{\text {th }}$ March 2017
In acute poisoning, one needs a high clinical suspicion, which can be developed by understanding the etiology and clinical features of commonly available poisons in their demographic area [12]. A strong clinical suspicion is crucial for prompt diagnosis and appropriate management of poisoning patients presenting to the ED. Public health professionals and emergency physicians must be abreast with updated information about epidemiology of poisoning, their clinical features and variations in patterns of poisoning among different districts, and states in India as they change rapidly [1,10,13-15]. 
Regional epidemiological data on poisoning aids public health departments in developing relevant prevention programs, and poison control centers; and aids hospital EDs in rationalizing resources in the management of poisoning, clinical research and disaster preparedness. In India, there is marked differences in patterns of poisoning between cities, smaller towns and villages. In urban areas, agents for poisoning are mainly household chemicals, alcohol, and medicines $[1,6]$.

However, in rural regions, common agents are plants, flowers, and seeds, or chemicals used in agriculture such as pesticides [10,16-19]. Mortality and morbidity due to pesticide poisoning, especially among farmers continues to be a major problem in India $[20,21]$.

Everyday due to poisoning 700 people die, and several thousand are affected globally [22,23]. Annual incidence of poisoning (suicidal, accidental, and homicidal) differs from 0.2 to 9.3 persons per 1,000 population in developed countries, which continues to rise annually globally [3,24]. Fatality rate was highest among 3 to 44 years of age, and the death rate was 0.5 per 1,00,000 children amidst children below 15 years of age [25].

In India, after hanging (45.6\%), poisoning $(27.9 \%)$ is the second most common means of suicide, which increased by $2 \%$ from 2014 (26\%) [21]. Number of fatalities due to poisoning increased by $18.5 \%$ in 2015 (28,445 deaths) in comparison to 2014 (23,162 deaths) [21]. In India, the fourth basic reason for death is poisoning [26]. Every year, for every one lakh population, five to six persons die of poisoning [27]. In the ED, $35 \%$ to $42 \%$ of the poisoning patients were treated, and discharge and about $74.4 \%$ were treated medically.

More than thirty lakh poisoning patients with 2,51,881 deaths are recorded every year globally, with developing countries accounting for $99 \%$ of mortalities due to poisonings, especially farmers [23]. In more than 12.5 lakh patients who were medically treated for poisoning in 2000, 4.4 lakh patients were of 0 to 19 years of age $[28,29]$.

The goal of this research is to define the epidemiological profile of patients registered in the ED with complaints of ingestion of poison; and to identify different types of poisons consumed, the duration of hospital stay and mortality due to these poisons.

\section{Materials and Methods}

Study Design, Settings, and Population- This study is a retrospective analysis of all consecutive patients registered to the ED with a history of poisoning, to define the epidemiological profile of poisoning patients, and identifying different types of poisons consumed, duration of stay and mortality due to these poisons. This study is conducted in the tertiary care university teaching hospital and a Level I trauma center in Chennai, India, for one year period between October 1st, 2013 to September 30th, 2014.

All patients irrespective of age and sex, registered in the ED with complaints of consumption of poison like medicines, alcohol, and chemical used in households, agriculture and industries were included in the study. Patient charts with incomplete data, patients diagnosed as food poisoning, pregnant women, and patients with snake bites, or scorpion stings or other insect bites were excluded from the study.

Methodology-Poisoning was established as exposure to any substances resulting in an emergency department visit. Patients attending the ED of the hospital with the history of suspected exposure to poison are clinically evaluated and resuscitated by the treating physician. A medico-legal case is registered for all poisoning cases. Identification of poison was done based on the statement of the patient/witness, or the smell of poisoning agents on the patient, identification of the brought specimen, and based on the characteristic clinical features of poison in the majority of cases. Decontamination, gastric lavage, oral carbon medicines, and antidotes were administered depending on the poison consumed.

The content of the gastric lavage is sent for laboratory examination to confirm the poison ingested. Emergency management involving airway patency, breathing with oxygenation and ventilation, circulation, and seizure management, along with central line insertion were done as per the patient's symptoms and clinical presentation. Decontamination was performed for all pesticide poisoning patients by clothing removal and a thorough wash in the decontamination room located at the entrance of the ED.

Data Collection-The medical charts of all patients with a discharge diagnosis of Poisoning during the study period from October 2013 to September 2014 were 
identified using the ICD-10-CM diagnosis codes categories T36-T65 in the search categories from the computerized medical records. Data from the medical records were collected in the preformatted questionnaire.

Data collected included patient's age, sex, marital status, years of marriage, occupation, the poisoning substance consumed, date and time of consumption, access to the poison, the reason for ingestion, intent, if gastric lavage was done, the antidote was given, disposition, and outcome of the patient.

\section{Result}

In this study, 317 patients were enrolled, with a male: female ratio of 1:1.21. A female predominance of 54.8\% was noted in the study. Men account for $45.1 \%$ patients, with a mean age of 27 years (SD 57.98, range 1 to 83 years) (Table 1.). The majority of the patients are of 15 to 24 years of age (31.86\%), followed by 25 to 34 years of age (26.18\%). Age and sex distribution of poisoning patients is shown in Figure 1.

On analysis of monthly distribution, the majority of patients presented to ED in June (12.93\%), followed by November $(10.09 \%)$ (Figure 2.). Seasonal variation in incidence of poisoning patients is illustrated in Figure 3. A maximum number of patients presented with poisoning to ED from 7 am to $12 \mathrm{pm} \mathrm{(31.54 \% ),} \mathrm{followed} \mathrm{by} 12$ pm to $6 \mathrm{pm}(29.33 \%)$. On analyzing occupation of the poisoning patients, students account for $30.6 \%$, homemakers $18.3 \%$, children below five years of age $11.35 \%$, and farmers $6.62 \%$ (Table 1.). Among 317 patients, $46.37 \%$ were married, and $54.6 \%$ were single. Among those married, $35.37 \%$ were married for 3 to 7 years, $21.76 \%$ were married for 7 to 15 years, and $20.4 \%$ were married for 0 to 2 years.

Out of 317 poisoning patients, $34.7 \%$ patients ingested pesticides, 30.28\% patients presented with tablet overdose, $14.82 \%$ patients consumed rodenticides and insecticides, and $3.47 \%$ patients presented with oleander seed poisoning (Table 2.).

The most common reason for ingestion of poison was a quarrel $(49.21 \%)$ with family members, spouse, or loved ones, followed by depression (27.12\%) (Figure 4.). On determining access to the poison, our study found $59.3 \%$ patients had access to the poison at their homes, and $19.87 \%$ patients brought their poison from a pharmacy. The intent for consuming poison was suicidal $(85.80 \%)$ in the majority of the patients, accidental in $13.25 \%$ patients and homicidal in less than one percent of patients (Table 3.).

Of the 317 patients, $67.82 \%$ patients were admitted to the ward and $32.17 \%$ patients in the ICU. Among 317 poisoning patients, $88 \%$ patient recovered and discharged home, $7.88 \%$ patients discharged against medical advice (AMA), and 4.1\% patients died in the hospital (Table 3.). All the 13 patients who died were admitted to the ICU. Among the 25 patients who went AMA, 23 were from the ICU, and two were from the ward.

Among the 279 patients who recovered and went home, 66 were from the ICU, and 213 were from the ward. Of the 13 patients who died, seven patients consumed organophosphate and carbamate insecticide poison, three patients consumed Rodenticides, and three patients consumed herbicide and fungicides. Of the 25 patients who were discharged AMA, nine patients consumed organophosphate and carbamate insecticides, six ingested benzodiazepine tablets, three consumed rodenticides, 3 drank corrosive agents, 2 ate herbicide and fungicides, and two ingested unspecified pesticides.

The mean length of stay at the hospital was five days (SD 18+/- 3 days, range 1 to 61 days). The mean length of stay at the hospital was five days (SD 18+/- 3 days, range 1 to 61 days). Among the hospitalized patients, 53.94\% were discharged within three days (Table 3.). 
Table 1. Profiling of poisoning patients.

\begin{tabular}{|c|c|c|c|c|}
\hline S. No & Features & & $\begin{array}{l}\text { Numbers } \\
(n-317)\end{array}$ & $\begin{array}{c}\text { Percentage } \\
(\%)\end{array}$ \\
\hline 1. & Sex & $\begin{array}{l}\text { Male } \\
\text { Female }\end{array}$ & $\begin{array}{l}143 \\
174\end{array}$ & $\begin{array}{l}45.1 \\
54.8\end{array}$ \\
\hline 2. & Age & $\begin{array}{l}5 \text { years } \\
5-14 \text { years } \\
15-24 \text { years } \\
25-34 \text { years } \\
35-44 \text { years } \\
45-54 \text { years } \\
55-64 \text { years } \\
65-74 \text { years } \\
>74 \text { years }\end{array}$ & $\begin{array}{c}36 \\
11 \\
101 \\
83 \\
38 \\
25 \\
7 \\
11 \\
5\end{array}$ & $\begin{array}{c}11.35 \\
3.47 \\
31.86 \\
26.18 \\
11.98 \\
7.88 \\
2.2 \\
3.47 \\
1.57\end{array}$ \\
\hline 3. & $\begin{array}{l}\text { Time of } \\
\text { Consumption }\end{array}$ & $\begin{array}{l}6 \text { am - } 6 \mathrm{pm} \\
\text { 6:01 pm- 5:59 am }\end{array}$ & $\begin{array}{l}193 \\
124\end{array}$ & $\begin{array}{l}60.88 \\
39.11\end{array}$ \\
\hline 4. & Marital Status & $\begin{array}{l}\text { Single } \\
\text { Married }\end{array}$ & $\begin{array}{l}170 \\
147\end{array}$ & $\begin{array}{l}53.62 \\
46.37\end{array}$ \\
\hline 5. & $\begin{array}{l}\text { Years } \\
\text { Marriage } \\
(n-147)\end{array}$ & $\begin{array}{l}0-2 \text { years } \\
3-7 \text { years } \\
7-15 \text { years } \\
16-25 \text { years } \\
>25 \text { years }\end{array}$ & $\begin{array}{l}30 \\
52 \\
32 \\
21 \\
12\end{array}$ & $\begin{array}{c}20.4 \\
35.37 \\
22.76 \\
14.28 \\
8.16\end{array}$ \\
\hline 6. & Occupation & $\begin{array}{l}\text { Students } \\
\text { Housewife } \\
\text { Business } \\
\text { Child } \\
\text { Job } \\
\text { Farmers } \\
\text { Engineers } \\
\text { Retired } \\
\text { Lecturer / Teacher }\end{array}$ & $\begin{array}{l}97 \\
58 \\
45 \\
36 \\
34 \\
21 \\
14 \\
7 \\
5\end{array}$ & $\begin{array}{c}30.6 \\
18.3 \\
14.2 \\
11.35 \\
10.72 \\
6.6 \\
4.41 \\
2.2 \\
1.57\end{array}$ \\
\hline
\end{tabular}

Table 2. Agents responsible for poisoning.

\begin{tabular}{|c|c|c|c|c|}
\hline S. No & \multicolumn{2}{|c|}{ Poisoning Agents } & $\begin{array}{l}\text { Number } \\
(\mathbf{n}-317)\end{array}$ & $\begin{array}{c}\text { Percentage } \\
(\%)\end{array}$ \\
\hline \multirow[t]{3}{*}{1.} & \multirow{3}{*}{ Pesticides } & Organophosphate and Carbamite Insecticide & 50 & 15.77 \\
\hline & & Herbicides and fungicide & 8 & 2.52 \\
\hline & & Unspecified pesticides & 52 & 16.4 \\
\hline \multirow[t]{5}{*}{2.} & \multirow{5}{*}{$\begin{array}{l}\text { Tablet } \\
\text { Overdose }\end{array}$} & Acetaminophen & 26 & 8.2 \\
\hline & & Antiepileptic and sedative hypnotic drugs & 10 & 3.15 \\
\hline & & Benzodiazepines & 47 & 14.82 \\
\hline & & oral hypoglycemic drugs & 8 & 2.52 \\
\hline & & Oral contraceptives & 5 & 1.57 \\
\hline \multirow[t]{3}{*}{3.} & \multirow{3}{*}{$\begin{array}{l}\text { Insecticide and } \\
\text { Rodenticides }\end{array}$} & Rodenticides & 39 & 12.3 \\
\hline & & Halogenated insecticides & 4 & 1.26 \\
\hline & & Other insecticides & 4 & 1.26 \\
\hline \multirow[t]{3}{*}{4.} & \multirow{3}{*}{$\begin{array}{l}\text { Corrosive } \\
\text { Agents }\end{array}$} & Corrosive Acids and acid like substances & 11 & 3.47 \\
\hline & & Corrosive alkalis and alkali like substances & 4 & 1.26 \\
\hline & & Unspecified corrosive substance & 15 & 4.73 \\
\hline 5. & \multicolumn{2}{|c|}{ Petroleum Products - Kerosene } & 18 & 5.67 \\
\hline 6. & \multicolumn{2}{|c|}{ Plant Poisons - Oleander Seed } & 11 & 3.47 \\
\hline 7. & \multicolumn{2}{|c|}{ Heavy Metals - Mercury } & 5 & 1.57 \\
\hline
\end{tabular}


Table 3. Access, intent, disposition, duration of stay and outcomes of Poisoning Patients.

\begin{tabular}{|c|c|c|c|c|}
\hline S. No & Features & & $\begin{array}{l}\text { Numbers } \\
(n-317)\end{array}$ & $\begin{array}{c}\text { Percentage } \\
(\%)\end{array}$ \\
\hline 1. & $\begin{array}{l}\text { Access to } \\
\text { Poison }\end{array}$ & $\begin{array}{l}\text { Home } \\
\text { Pharmacy } \\
\text { Neighborhood Shop } \\
\text { Farm } \\
\text { Industry }\end{array}$ & $\begin{array}{c}188 \\
63 \\
45 \\
20 \\
1\end{array}$ & $\begin{array}{c}59.3 \\
19.78 \\
14.19 \\
6.3 \\
0.315\end{array}$ \\
\hline 2 . & Intent & $\begin{array}{l}\text { Suicidal } \\
\text { Accidental } \\
\text { Homicidal }\end{array}$ & $\begin{array}{c}272 \\
42 \\
3 \\
\end{array}$ & $\begin{array}{c}85.8 \\
13.25 \\
0.94\end{array}$ \\
\hline 3. & Disposition & $\begin{array}{l}\text { ICU } \\
\text { Ward }\end{array}$ & $\begin{array}{l}102 \\
215\end{array}$ & $\begin{array}{l}32.17 \\
67.82\end{array}$ \\
\hline 4. & Hospital Stay & $\begin{array}{l}1 \text { - } 3 \text { days } \\
4 \text { - } 7 \text { days } \\
>7 \text { days }\end{array}$ & $\begin{array}{c}171 \\
91 \\
55\end{array}$ & $\begin{array}{c}53.94 \\
28.7 \\
17.35\end{array}$ \\
\hline 5. & Outcomes & $\begin{array}{l}\text { Dead } \\
\text { AMA } \\
\text { Recovered }\end{array}$ & $\begin{array}{c}13 \\
25 \\
279 \\
\end{array}$ & $\begin{array}{c}4.1 \\
7.88 \\
88.01 \\
\end{array}$ \\
\hline
\end{tabular}

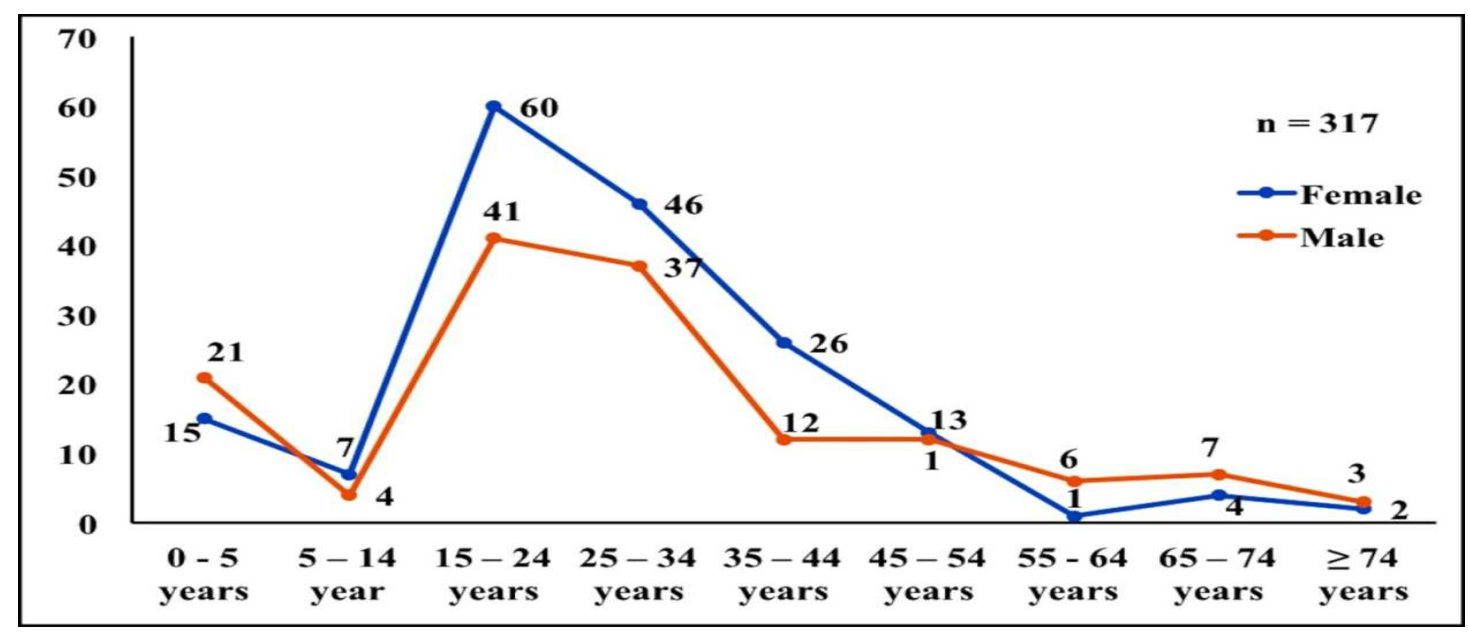

Figure 1. Age and Sex distribution of Poisoning Patients

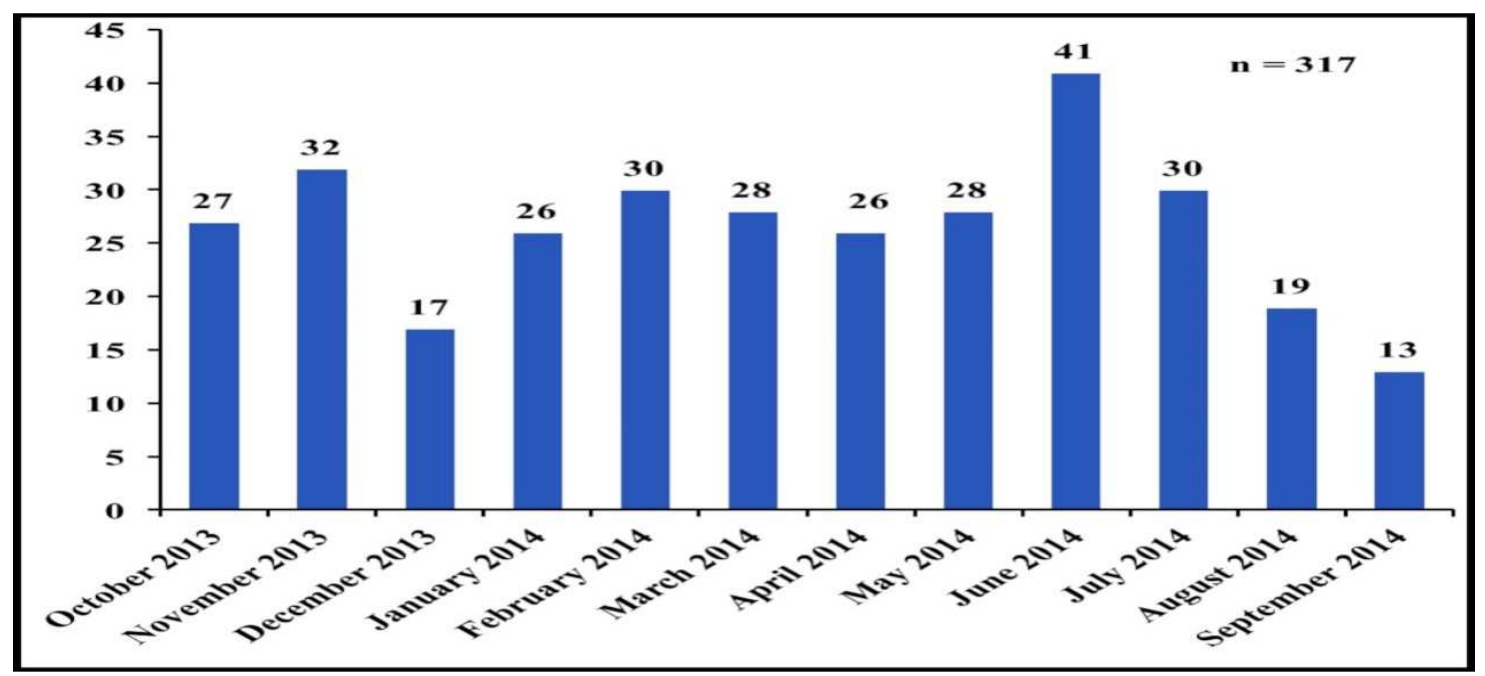

Figure 2. Month wise distribution of incidence of Poisoning Patients 


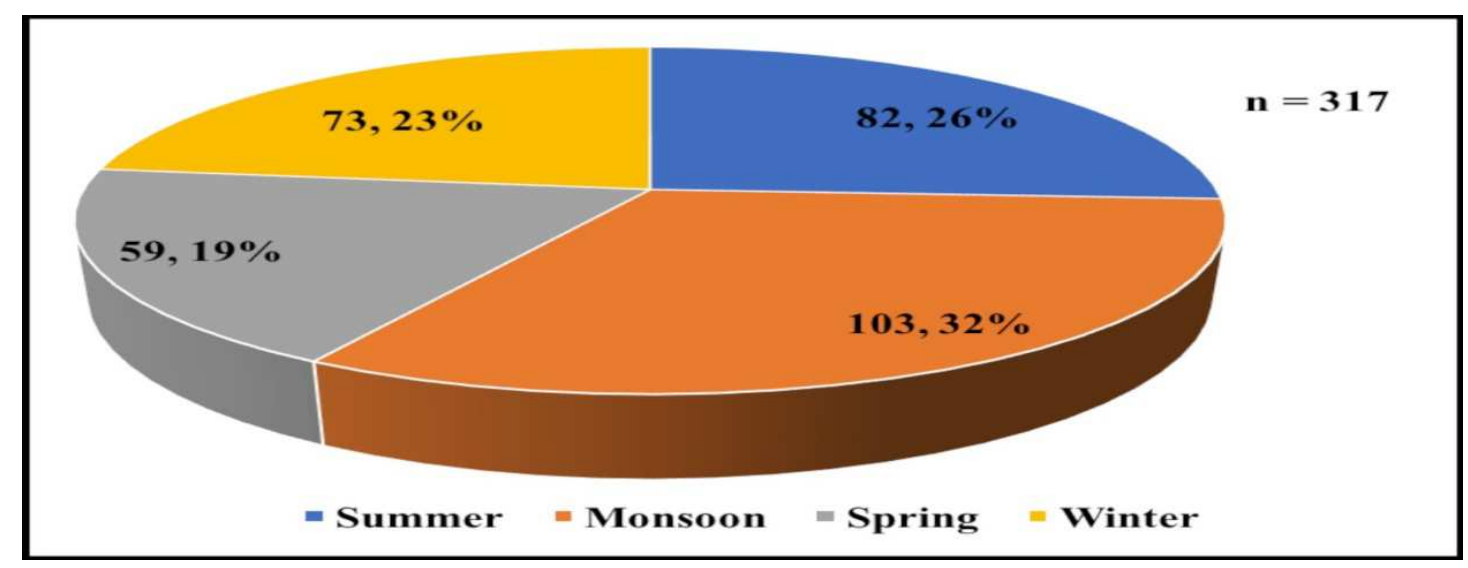

Figure 3. Seasonal Variation in incidence of Poisoning

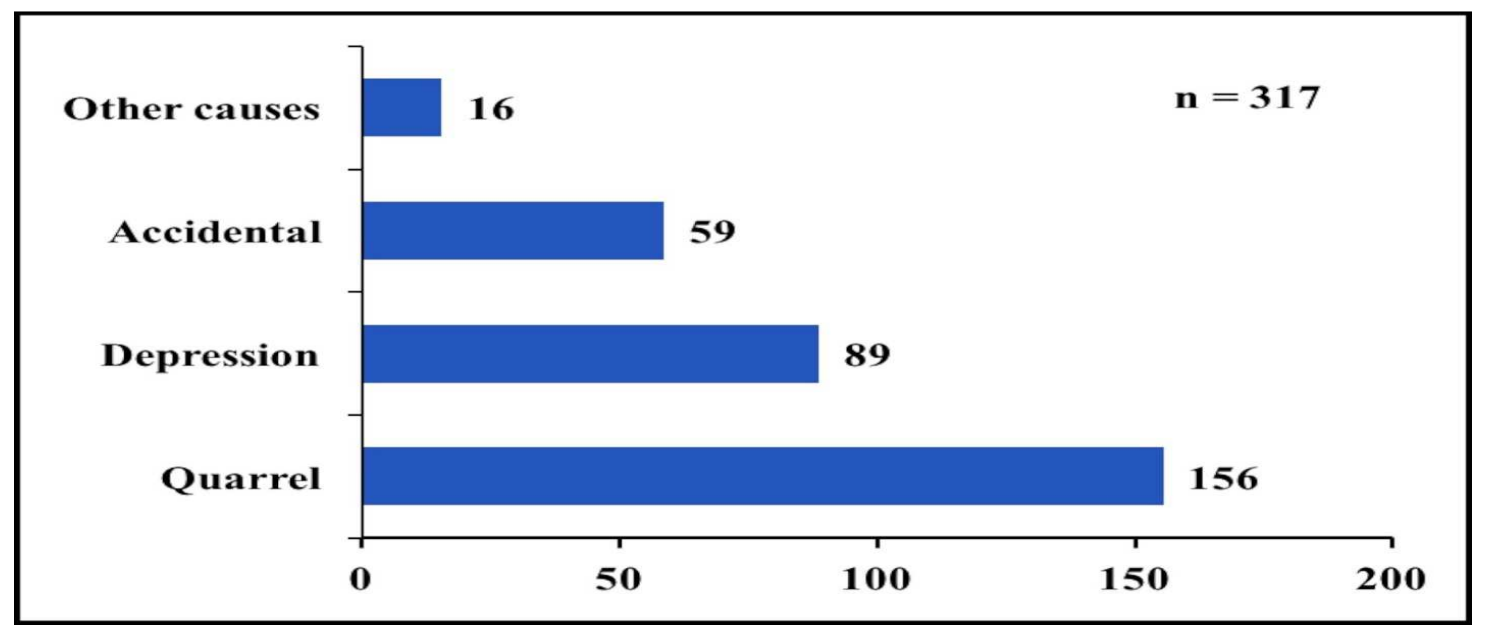

Figure 4. Reasons for Poison Consumption.

\section{FIGURE LEGENDS}

Figure 1. Age and Sex distribution of Poisoning Patients

Figure 2. Month wise distribution of incidence of Poisoning Patients

Figure 3. Seasonal Variation in incidence of Poisoning

Figure 4. Reasons for Poison Consumption

\section{Discussion}

A total of 317 patients were registered in the ED with a history of poisoning in this study, which accounted for $1 \%$ of the annual ED visits. However, the poisoning rate in relation to the annual ED visits ranged from $0.26 \%$ to $0.7 \%$ in western countries [3, 30, 31]. This high incidence of poisoning can be credited to the easy availability of poisons in India and the prevailing dogma is that mortality due to poisoning is with very less suffering compared to other means. This study observed a high female preponderance, with a ratio of 1:1.21 (male: female). Similar observations were found in other studies [20,32,33].
This pattern can be attributed to increasing challenges, stress, family burden, and abuse women are prone to in the Indian society than men.

The majority of the patients $(46.68 \%)$ in this study were less than 25 years of age, comparable to other research studies $[3,12,34]$. The highest number of acute adults poisoning patients was observed in 15 to 24 years old, comparable to other study findings $[7,35]$. The high number of poisoning patients below 25 years old, the Millennials, can be attributed to increased peer pressure, competitiveness, stress, and heavy expectations from 
family and loved ones. A majority of unintentional/ accidental poisoning patients in this study were children between 0 to 5 years of age. Similar high rates of unintentional poisoning among children 0 to 5 years old were found in other studies [36]. This significant number of accidental poisoning among children can be attributed to chemicals and poisons stored in easily accessible places and lack of awareness among parents and family members and the society, resulting in increase in accidental poisoning among children [37].

The popular time for ingestion of poison was the daytime (6 am to $6 \mathrm{pm}$ ), which is comparable to other study findings [38-40]. This can be attributable to stress during working hours at the office, school, farm, or at home, making the victim more helpless to consume poison out of impulsivity. A bulk of the poisoning patients in this study presented to the ED in January and June. In this study, monsoon was the popular season for ingestion of poison, followed by summer. This seasonal variation was comparable to other investigations where there were more patients with the history of poisoning in the monsoon $[41,42]$. In this study, June was the popular month, followed by July, and November for poisoning, comparable to other studies, where June, July, and August were the popular months [42]. This peak in June can be associated with the release of $10^{\text {th }}$, higher secondary and college entrance exams results. Moreover, the peak in July and November can be connected to monsoon rains where farmers are either affected by scanty rainfall in the drought areas or heavy rains destroying their crops.

A significantly higher number of poisoning patients in this study are unmarried, as there were a large number of children with accidental poisoning and students due to failure in examinations at school, love affairs, stress and peer pressure. The majority of the suicidal poisoning was observed in married patients, mostly females, which was comparable to other investigations [26]. A high number of patients in this study were married for 3 to 7 years, followed by 0 to 2 years. This can be due to abuse, marriage related issues, dowry related issues, extramarital affairs, divorce, impotence or infertility illness, unemployment or other family problems [21].

Most the poisoning patients based on their occupations were students, followed housewives, and businessmen. A significant number of the patients were farmers $(6.62 \%)$. A similar study observed housewives accounted for the greatest number of the poisoning patients, then came farmers, shopkeepers, and laborers [43]. Moreover, maximum number of the patients in this study had access to the poison either at their homes, or brought their poison from a pharmacy or a shop next to their home, or at their farms.

Furthermore, the intent for poisoning in the greatest number of the patients in this study was suicidal, followed by accidental poisoning, which was comparable to other investigations [20,26,44]. Three cases of homicidal poisoning (less than one percent) were reported in this study. On the psychiatric assessment of all poisoning patients, the reason for ingestion of poison in a maximum number of patients in this study was due to a quarrel with family members or loved ones. Other causes were depression, acute stress, family issues, failure in examinations, financial problems, other psychiatric illness and accidental poisoning. The psychiatric assessments in this study were comparable to findings in other studies $[20,44]$.

The common type and classes of poisons consumed in this study include pesticides, tablet overdose; rodenticides and insecticides; corrosive agents; petroleum products; plant poison, and heavy metals. Among these poisons, unspecified pesticides were consumed by a maximum number of patients, followed by Organophosphate and carbamate insecticide poison, Benzodiazepine tablet overdose, Rodenticides, Acetaminophen tablet overdose and Petroleum products. A significant number of patients did present with Oleander seed poison.

Studies also found pesticides like Organophosphates to be the predominant cause of poisoning [20,26,38]. As a maximum number of communities in South India are farming communities, pesticides like organophosphate and carbamate insecticide poison are the most commonly used agrochemicals, abundantly and readily available in local shops in South India, making it a favorable agent for suicidal poisoning. A retrospective study on 7,000 poisoning cases found Benzodiazepines as the common cause of poisoning, which is comparable to our findings that Benzodiazepines is the most prevalent form of tablet overdose followed by analgesic agents, acetaminophens [45].

A majority of the patients $(67.8 \%)$ in this study were hospitalized for further treatment and observation. A significant number of patients $(32.17 \%)$ were admitted 
to the ICU for intensive monitoring and treatment. In contrast, only $3.7 \%$ were admitted to the ICU, while $79.6 \%$ were discharged home from the ED, 5.2\% left the ED AMA and just $6.7 \%$ patients were hospitalized in another study [34]. Moreover, a bulk of the patients $(88 \%)$ in this study completely recovered and were discharged home, while $7.88 \%$ of the patients left the hospital AMA.

A mortality rate of $4.1 \%$ due to poisoning was observed in this study. There were no deaths in the ward or ED. The patients who died in this study were admitted to the ICU, with consumption of these three classes of poisons: a). Organophosphate and carbamate insecticide poisoning, b). Rodenticides, and c). Herbicide and fungicides. The specific mortality rate could not be determined as 25 patients $(7.88 \%)$ left the hospital AMA, 23 patients from the ICU and two patients from the ward. In this study, the fatality rate was lower compared to other studies $[20,43,46]$. In this study, 53\% of the patients were discharged from the hospital within first three days of hospitalization, $28.7 \%$ discharged within four and seven days of admission, and $17.35 \%$ patients were treated for seven days or more in the hospital. These findings were comparable to results from other studies [34].

\section{Conclusion}

We were able to demonstrate the epidemiological profile of poisoning patients registered in the emergency department, along with the common poisons used, duration of hospital stay and mortality due to the same. Common household items like rodenticides, insecticides, mosquito repellent, bathroom cleaners, and kerosene, which are commonly used as poisons should be clearly labeled, locked and safely stored at homes to prevent accidental poisoning among children and dissuade suicidal poisoning among adults. Legislation and guidelines restricting sales of pesticides to those without farm lands should be strictly implemented to prevent non-farmers from having access to these chemicals. Similarly, sales of benzodiazepines, antihistamines and other sedatives must be regulated through strict enforcement of providing them only on presentation of a valid prescription from a licensed medical practitioner. This will decrease poisoning due to restricted access to these drugs. A long-term strategy that will include more far reaching results is one that involves a two-step verification process by pharmacies licensed to provide restricted medication. A program where they can contact the doctor's office/clinic or verify the authenticity of the prescription would be ideal. While not all doses of these drugs can prove to be fatal, the lack of knowledge or inadequate information on them certainly can be.

If more people are made aware of the effects of the drugs they have been prescribed, and the consequence of abusing them, or overdosing on them, the effect will most definitely be felt in the number of poisoning incidents presenting in the ED. Community awareness programs, and campaigns, poison control centers and suicide help lines, targeted towards the youth, especially women, can help significantly reduce the incidence of poisoning.

Source(s) of support: No financial or other manner of support obtained

Presentation at a meeting: Not presented at any conference or seminars

Conflicting Interest (If present, give more details): None to disclose

\section{Funding: Nil, Conflict of interest: None}

Permission of IRB: Yes

\section{References}

1. Watson WA, Litovitz TL, Klein-Schwartz W, Rodgers GC Jr, Youniss J, Reid N, Rouse WG, Rembert RS, Borys D. 2003 Annual report of the American Association of Poison Control Centers Toxic Exposure Surveillance System. Am J Emerg Med. 2004 Sep;22 (5):335-404.

2. Akkose S, Fedakar R, Bulut M, Armagan E, Cebicci H. Acute poisoning in adults in the years 1996-2001 treated in the Uludag University Hospital, Marmara Region, Turkey. Clin Toxicol 2005 Jan 1;43(2):105109. DOI: $10.1081 /$ CLT-50429

3. Hanssens Y, Deleu D, Taqi A. Etiologic and demographic characteristics of poisoning: a prospective hospital-based study in Oman. J Toxicol Clin Toxicol. 2001;39(4):371-80.

4. Bruyndonckx RB, Meulemans AI, Sabbe MB, Kumar AA, Delooz HH. Fatal intentional poisoning cases admitted to the University Hospitals of Leuven, Belgium from 1993 to 1996. European Journal of Emergency Medicine 2002 Sep 1;9(3):238-243. PMID: 12394620. 
5. Hatzitolios AI, Sion ML, Eleftheriadis NP, Toulis E, Efstratiadis G, Vartzopoulos D, et al. Parasuicidal poisoning treated in a Greek medical ward: epidemiology and clinical experience. Hum Exp Toxicol 2001 Dec; 20(12):611-617. DOI: 10.1191/ 096032701718890595.

6. Burillo-Putze G, Munne P, Dueñas A, Pinillos MA, Naveiro JM, Cobo J, Alonso J; Clinical Toxicology Working Group, Spanish Society of Emergency Medicine (SEMESTOX). National multicentre study of acute intoxication in emergency departments of Spain. Eur J Emerg Med. 2003 Jun;10(2):101-4.

7. Goksu S, Yildirim C, Kocoglu H, Tutak A, Oner U. Characteristics of acute adult poisoning in Gaziantep, Turkey. J Toxicol Clin Toxicol. 2002;40(7):833-7.

8. Lamireau T, Llanas B, Kennedy A, Fayon M, Penouil F, Favarell-Garrigues JC, Demarquez JL. Epidemiology of poisoning in children: a 7-year survey in a paediatric emergency care unit. Eur J Emerg Med. 2002 Mar; 9(1): 9-14.

9. Tüfekçi IB, Curgunlu A, Sirin F. Characteristics of acute adult poisoning cases admitted to a university hospital in Istanbul. Hum Exp Toxicol. 2004 Jul;23 (7):347-51.

10. Fernando R. The National Poisons Information Centre in Sri Lanka: the first ten years. J Toxicol Clin Toxicol. 2002;40(5):551-5.

11. Oxford English Dictionary. [Internet]. 2015. "poison,n.".Availableat:http://www.oed.com/viewdictio naryentry/Entry/146669. Accessed February 19th, 2017.

12. Lau FL. Emergency management of poisoning in Hong Kong. Hong Kong Med J. 2000 Sep;6(3):288-92.

13. Staikowsky F, Theil F, Mercadier P, Candella S, Benais JP. Change in profile of acute self drugpoisonings over a 10-year period. Hum Exp Toxicol. 2004 Nov;23(11):507-11.

14. Singh D, Jit I, Tyagi S. Changing trends in acute poisoning in Chandigarh zone: a 25-year autopsy experience from a tertiary care hospital in Northern India. The American Journal of Forensic Medicine and Pathology 1999 Jun 1;20(2):203-210. PMID: 10414665.
15. Sharma BR, Harish D, Sharma V, Vij K. Poisoning in Northern India: changing trends, causes and prevention thereof. Medicine, science and the law 2002 Jul 1;42(3):251-257. PMID: 12201071.

16. Ab Rahman AF. Drug and chemical poisoning admissions at a teaching hospital in Malaysia. Hum Exp Toxicol 2002 July 1;21(7):377-381. PMID: 1226 9700 .

17. Van Der Hoek W, Konradsen F. Risk factors for acute pesticide poisoning in Sri Lanka. Tropical Medicine \& International Health 2005 Jun 1;10(6):589596. DOI: 10.1111/j.1365-3156.2005.01416.x

18. Hwang K, Lee E, Hong S. Paraquat intoxication in Korea. Archives of Environmental Health: An International Journal 2002 Mar 1;57(2):162-166. DOI: 10.1080/00039890209602931.

19. Dong X, Simon MA. The epidemiology of organophosphate poisoning in urban Zimbabwe from 1995 to 2000. International journal of occupational and environmental health 2001 Oct 1;7(4):333-338. DOI: $10.1179 / 107735201800339191$.

20. Kondle Raghu PS, Kumar SS, Gopal S, Shaik MV, Ahammed B. Incidence and Outcome of Poisoning Patients in a Tertiary Care Teaching Hospital. Asian Journal of Pharmacology and Toxicology 2015 Feb 25; $3(7): 23$.

21. National Crime Records Bureau. Accidental death and suicides in India 2015. National Crime Records Bureau 2016 August 1:192-206.

22. Zine KU, Mohanty AC. Pattern of acute poisoning at Indira Gandhi Medical College and Hospital, Nagpur. J Ind Aca For Med 1998 Apr;20(2):37-39.

23. World Health Organization. Guidelines for poison control. 1st ed. Geneva: World Health Organization (WHO); 1997. ISBN: 9241544872.

24. Litovitz TL, Klein-Schwartz W, Caravati EM, Youniss J, Crouch B, Lee S. 1998 Annual report of the American Association of Poison Control Centers toxic exposure surveillance system. Am J Emerg Med 1999 Sep 1; 17 (5): 435-487. PMID: 1049 6515. 
25. Fingerhut LA, Cox CS. Poisoning mortality, 19851995. Public Health Rep. 1998 May-Jun;113(3):218-33.

26. Unnikrishnan B, Singh B, Rajeev A. Trends of acute poisoning in South Karnataka. Kathmandu Univ Med J (KUMJ). 2005 Apr-Jun;3(2):149-54.

27. Narayana Reddy KS. Toxicology, General consideration. 29th ed. New Delhi: Jaypee Brothers Medical Publishers; 2010.

28. Miller TR, Finkelstein AE, Zaloshnja E, Hendrie D. The cost of child and adolescent injuries and the savings from prevention. In: Karen DeSafey Liller, editor. Injury prevention for children and adolescents: research, practice, and advocacy. 1st ed. Washington DC: American Public Health Association; 2006. p. 15-64. ISBN: 978-0-87553-005-5.

29. Stevens JA, Corso PS, Finkelstein EA, Miller TR. The costs of fatal and non-fatal falls among older adults. Inj Prev. 2006 Oct;12(5):290-5.

30. Thomas SH, Bevan L, Bhattacharyya S, Bramble MG, Chew K, Connolly J, Dorani B, Han KH, Horner JE, Rodgers A, Sen B, Tesfayohannes B, Wynne H, Bateman DN. Presentation of poisoned patients to accident and emergency departments in the North of England. Hum Exp Toxicol. 1996 Jun;15(6):466-70.

31. McCaig LF, Burt CW. Poisoning-related visits to emergency departments in the United States, 19931996. J Toxicol Clin Toxicol. 1999;37(7):817-26.

32. Bajracharya MR, Deo KMK, Pahari SK. Age and gender distribution in deliberate self-poisoning cases. Post-GraduateMedicalJournalof NAMS2008 Jun1;8(01)

33. Paudyal BP. Poisoning : Pattern and profile of admitted cases in a hospital in Central Nepal. JNMA J Nepal Med Assoc. 2005 Jul-Sep;44(159):92-6.

34. Gloglu C, Kara IH. Acute poisoning cases admitted to a university hospital emergency department in Diyarbakir, Turkey. Hum Exp Toxicol 2005 Feb;24(2):49-54. DOI: 10.1191/0960327105ht499oa.

35. Ozköse Z, Ayoglu F. Etiological and demographical characteristics of acute adult poisoning in Ankara, Turkey. Hum Exp Toxicol. 1999 Oct;18(10):614-8.
36. Xiang Y, Zhao W, Xiang H, Smith GA. ED visits for drug-related poisoning in the United States, 2007. Am J Emerg Med. 2012 Feb;30(2):293-301. doi: 10. 1016 /j. ajem.2010.11.031. Epub 2011 Mar 2.

37. Kanchan T, Menezes RG. Mortalities among children and adolescents in Manipal, Southern India. J Trauma. 2008 Jun;64(6):1600-7. doi: 10.1097/TA. 0b0 13e3180a032a1.

38. Kanchan T, Menezes RG, Kumar TM, Bakkannavar SM, Bukelo MJ, Sharma PS, et al. Toxicoepidemiology of fatal poisonings in Southern India. Journal of forensic and legal medicine 2010 Aug;17(6):344-347. PMID:20650426

39. Sinha US, Kapoor AK, Agnihotri AK, Srivastava PC. A profile of poisoning cases admitted in SRN Hospital, Allahabad with special reference to aluminium phosphide poisoning. Journal of Forensic Medicine \& Toxicology 1999 Jun 1;16(1):43-42. ISSN: 0972-0448.

40. Senanayake N, Peiris H. Mortality due to poisoning in a developing agricultural country: trends over 20 years. Hum Exp Toxicol. 1995 Oct;14(10):808-11.

41. Dhattarwal SK, Dalal SS. Profile of deaths due to poisoning in Rohtak, Haryana in the year 1995. Journ Forensic Med Toxicol 1997;14:51.

42. Sheikh MI, Agarwal SS, Kumar L, Jhaveri S. Changing trends of poisoning in Surat. International Journal of Medical Toxicology \& Legal Medicine 2004 Jun;6(2):17-21. ISSN:0972-0448

43. Banerjee I, Tripathi SK, Roy AS. Clinicoepidemiological characteristics of patients presenting with organophosphorus poisoning. North American journal of medical sciences 2012 Mar 1;4(3):147. PMID: 22454830

44. Ramesha KN, Rao KB, Kumar GS. Pattern and outcome of acute poisoning cases in a tertiary care hospital in Karnataka, India. Indian J Crit Care Med. 2009 Jul-Sep;13(3):152-5. doi:10.4103/0972-5229. 58541 .

45. Abdollahi M, Jalali N, Sabzevari O, Hoseini R, Ghanea T. A retrospective study of poisoning in Tehran. J Toxicol Clin Toxicol. 1997;35(4):387-93. 
46. Zaheer MS, Aslam M, Gupta V, Sharma V, Khan SA. Profile of poisoning cases at a North Indian tertiary care hospital. Health Popul Perspect Issues 2009; 32:176-183.

\section{How to cite this article?}

Srihari C, Ramakrishnan T.V, Aditya M. Epidemiological profile of poisoning patients in the emergency department of a tertiary care teaching hospital in South India. Int J Med Res Rev 2017;5(03):212-222 doi:10.17511/ijmrr. 2017.i03.01. 